\title{
Apolipoprotein E/Intrauterine Undernutrition Interaction and Hypercholesterolemia in Children
}

\author{
P. SZITÁNYI ${ }^{1}$, H. PISTULKOVÁ $\dagger^{2}$, J. A. HUBÁČEK ${ }^{2,3}$, H. STUCHLÍKOVÁ ${ }^{3}$, \\ R. POLEDNE ${ }^{2,3}$
}

${ }^{1}$ Department of Pediatrics, First Faculty of Medicine, Charles University, General University Hospital, Prague, ${ }^{2}$ Institute for Clinical and Experimental Medicine, Department of Experimental Medicine, Prague, ${ }^{3}$ Cardiovascular Research Center, Prague, Czech Republic

Received May 2, 2007

Accepted October 1, 2007

On-line November 30, 2007

\begin{abstract}
Summary
The inconsistency of data regarding intrauterine programming of cardiovascular risk factors may be largely caused by genetic predisposition and later lifestyle. We analyzed whether low birth weight and apolipoprotein $\mathrm{E}$ (Apo $\mathrm{E}$ ) polymorphism participate in the onset of hypercholesterolemia in children. Our approach was based on hypothesis that genetically enhanced susceptibility of different individuals might influence the effects of intrauterine programming. Two groups were selected from 2000 children at the beginning of an ongoing study: high-cholesterol group (HCG, $\mathrm{n}=67$ ) and low-cholesterol group as a control ( $L C G, n=72)$. Both groups were divided into tertilles according to birth weight and we compared birth weight and apo $\mathrm{E}$ gene polymorphism between and within groups. The birth weight in HCG was $0.3 \mathrm{~kg}$ lower than the controls $(p<0.001)$. The frequency of apoE4 was $31 \%$ in HCG and only $10 \%$ in LCG. The frequency of apoE4+ genotypes was not significantly different between tertilles based on birth weight in HCG. We suppose that intrauterine undernutrition, demonstrated by a lower birth weight, participates in the development of hypercholesterolemia already in childhood. The effects of low birth weight and the candidate gene - apoE, are synergic.
\end{abstract}

\section{Key words}

Low birth weight $\bullet$ Hypercholesterolemia $\bullet$ Apolipoprotein E

\section{Corresponding author}

P. Szitányi, Department of Pediatrics and Adolescent Medicine, First Faculty of Medicine, Charles University, General Teaching Hospital, Ke Karlovu 2, 12109 Prague, Czech Republic. Fax +420224923 515. E-mail: szitanyi@yahoo.com, peter.szitanyi@vfn.cz
Atherogenesis is a process affected by a variety of different mechanisms, for which we have no complete explanation. The idea that the pathogenesis of coronary heart disease (CHD) begins already in childhood is generally accepted. It is also generally recognized that dietary manipulation in the early life of individuals modulates cholesterol metabolism in adulthood (Hahn et al. 1989).

Low birth weight $(\mathrm{BW})$ has been proved as a risk factor for CHD. The concept of an intrauterine effect on later function is based on the extensive body of data emerging from epidemiological studies. So-called programming theory proposed that susceptibility to CHD is determined already in utero (Barker et al. 1995). The strong association between low BW, high blood pressure (Law et al. 1993, Whincup et al. 1995), development of insulin resistance (Barker et al. 1993a) and non-insulin dependent diabetes (Phillips et al. 1994) was described. The effect on the development of hypercholesterolemia in later life is still uncertain (Barker et al. 1993b, Stanner et al. 1997). This hypothesis was also supported by some experimental models (Szitányi et al. 2000). The primary cause for all of these risks manifesting themselves in adulthood could be the intrauterine undernutrition leading to long-term morphological and metabolic defects, but the inconsistency of results from studies with various design (Stanner et al. 1997, Lumen at al. 1997) has led to criticism of this programming theory (Jones et al. 1998).

The reason may be that the effect of 
Table 1. Mean birth weight $(\mathrm{kg})$, lipoprotein concentrations $(\mathrm{mmol} / \mathrm{l})$ and apoE4 genotype frequencies in tertilles according the birth weight of LCG and HCG and in whole groups $\left({ }^{*}, \#, \$, \S p<0.01\right.$, S.D. in brackets).

\begin{tabular}{llllll}
\hline Parameter & Group & First tertille & Second tertille & Third tertille & Whole group \\
\hline Birth weight & LCG & $3.00(0.23)$ & $3.52(0.14)$ & $3.94(0.21)$ & $3.48(0.43)^{*}$ \\
$(\mathrm{~kg})$ & HCG & $2.67(0.40)$ & $3.20(0.13)$ & $3.78(0.26)$ & $3.21(0.54)^{*}$ \\
LDL-C & LCG & $2.18(0.54)$ & $2.32(0.42)$ & $2.45(0.61)$ & $2.30(0.54)^{\#}$ \\
$(\mathrm{mmol} / \mathrm{l})$ & HCG & $4.07(0.56)$ & $3.99(0.72)$ & $3.83(0.58)$ & $3.97(0.63)^{\#}$ \\
HDL-C & LCG & $1.23(0.26)$ & $1.36(0.28)$ & $1.19(0.27)$ & $1.25(0.28)^{\S}$ \\
$(\mathrm{mmol} / \mathrm{l})$ & HCG & $1.43(0.56)$ & $1.46(0.32)$ & $1.45(0.37)$ & $1.44(0.33)^{\$}$ \\
apoE4+ & LCG & $3 / 24$ & $2 / 24$ & $2 / 24$ & $7 / 72^{\S}$ \\
& HCG & $9 / 23$ & $7 / 22$ & $5 / 22$ & $21 / 67^{\S}$ \\
\hline
\end{tabular}

undernutrition depends on the genetic background of each individual. To assess the effect of genetic predisposition and low BW, we retrospectively analyzed the birth weights and apo $\mathrm{E}$ polymorphism in a group of hypercholesterolemic children and in those of a control group.

Two groups of probands were compared in the study. A high cholesterol group (HCG, 95-100 percentile) and a low cholesterol group (LCG, 5-10 percentile) had been selected from 2000 children (10-11 years old, of complete biological families in Prague). The HCG consists of 93 children with cholesterolemia exceeding the $95^{\text {th }}$ percentile of the distribution curve $(>5.5 \mathrm{mmol} / \mathrm{l})$, the LCG of 92 children with cholesterolemia between the $5^{\text {th }}$ and $10^{\text {th }}$ percentile (a study desirable range). There were no differences in actual BMI, insulin and thyroxin concentrations or in recent diet between the two groups (analysed by 3-days questionare), whereas LDL-C concentration was by definition (Table 1) almost twice as high in the HCG group (Pistulková et al. 1991, Poledne et al. 1994).

A venous blood sample for lipoprotein analysis had been drawn after an overnight fasting (12 hours). Total cholesterol (TC) triglycerides (TG) and cholesterol in all fractions had been determined on Hoffman-LaRoche COBAS MIRA autoanalyzers with enzymatic Boehringer Mannheim kits. HDL-C was analyzed in the supernatant after apoB-containing particles were precipitated by the phosphotungstate method. LDL-C was analyzed after fractional ultracentrifugation in fractions between 1.009 and 1.063. BW was obtained from questionnaires completed by the children's mothers and was confirmed by data from hospital records. Only one family displayed familial hypercholesterolemia ( $\mathrm{FH}$, one of parents with $\mathrm{TC}$ $>8 \mathrm{mmol} / \mathrm{l}$ and history of premature CHD before 55 years of age), all others had polygenous hypercholesterolemia (PHC) or familial combined hyperlipoproteinemia (FCHL). Criteria for FCHL were TC $>6.5 \mathrm{mmol} / \mathrm{l}$ plus TG $>2.2 \mathrm{mmol} / \mathrm{l}$ at least in one of parents. PHC was characterized by TC $>6.5 \mathrm{mmol} / \mathrm{l}$ at least in one of parents.

For this study, 25 HCG children and 20 LCG children were excluded because it was impossible to confirm BW data from hospital records leaving 67 and 72 children in these groups, respectively.

The apoE genotype was determined by PCRRFLP method (Hixson et al. 1990).

Data were expressed as mean ( \pm S.D.) and analyzed by unpaired Student's $t$ test and $\chi^{2}$ test.

Of the 13 polymorphisms in 11 genes analyzed, some differed between these groups (apoE, LPL, HMGCoA reductase, apoAII, LDL-receptor) (Hubáček et al. 2004). Among them, the effect of apoE gene was by far the most important (Poledne et al. 1994). The mean BW of HCG was significantly lower than that of LCG $(\mathrm{p}<0.001)$ (Table 1). The distribution of BW in the HCG was skewed towards lower values (Fig. 1). Six out of the HCG children and none from the LCG children had a BW under $2.5 \mathrm{~kg}$, the usual borderline of hypotrophic children $(\mathrm{p}<0.05)$. Almost $40 \%$ of the HCG had a BW under $3.0 \mathrm{~kg}$. To determine the relationship between intrauterine undernutrition (demonstrated by a low BW) and the direct effect of the most influential candidate gene, analysis of subgroups was performed. Both groups were divided into tertilles according to $\mathrm{BW}$, starting from the lowest $\mathrm{BW}$ in the $1^{\text {st }}$ tertille. The mean value of LDL-C tended to increase from the $1^{\text {st }}$ tertille to the $3^{\text {rd }}$ tertille in LCG and oppositely to decrease in HCG. However, these differences did not reach statistical significance. The frequency of "disadvantageous" genotypes having the E4 allele was 31 $\%$ in the HCG but only $10 \%$ in the LCG $(\mathrm{p}<0.01)$. The 


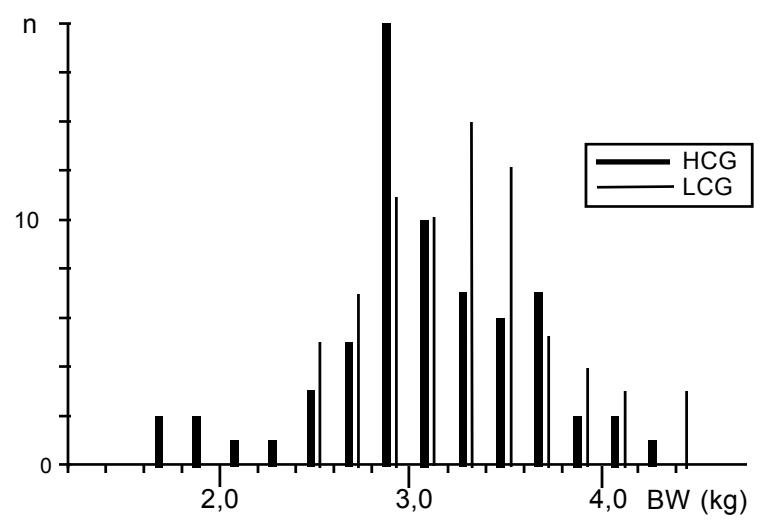

Fig. 1. Distribution curve of birth weight $(B W, \mathrm{~kg})$ in high cholesterol group (HCG) and low cholesterol group (LCG).

distribution of "disadvantageous" apoE4+ genotypes was low and similar in all LCG tertilles. The distribution of these genotypes in the HCG subgroups was 9, 7 and 5, respectively, but this trend did not reach statistical significance by the $\chi^{2}$ test (Table 1 ).

Intrauterine growth retardation, manifested as a lower BW, may imprint pathological defects (Barker et al. 1995) in metabolism and organ functions. In such a situation hypertension (Law et al. 1993, O'Sullivan et al. 2002), insulin resistance (Phillips et al. 1994) and probably also hyperlipoproteinemia (Barker et al. 1993b) might appear after the exposure to the Western life-style for several decades.

Two groups of children (HCG and LCG) with assumed different sensitivity to the diet were compared. No differences in dietary records were found and total fat consumption was $40 \%$ of the total energy intake with $80 \%$ of the fat of animal origin in both groups (typical Czech diet in the time of study - high fat, high sodium, low fiber intake, with low proportion of fresh vegetable and fruit, high red meat, practically no fish intake).

The genetic background of this different sensitivity was proved by differences in genotype frequencies (Hubáček et al. 2004), of which the apoE gene was the most important.

In our retrospective study HCG children have a lower BW than LCG children and the number of children with a BW under $2.5 \mathrm{~kg}$, which is usual borderline of hypotrophy, was six in HCG and none in LCG. These facts imply that intrauterine undernutrition also participates, with hypercholesterolemia onset in HCG children even as young as 10-11 years.

It was shown (Infante-Rivard et al. 2003) that babies born with intrauterine growth retardation has less often transmitted protective apoE2 allele. This is supporting the hypothesis of Barker, but lipid parameters were not determined as a clinical linkage (Infante-Rivard et al. 2003). Another two studies dealing with high TC, IUGR and apoE gene polymorphism have confirmed the association of high TC and low birth weight. Akisu et al. (2004) did not find differences in the distribution of apoE gene polymorphism between the IUGR and control groups. Garces et al. (2002) concluded greater effect of the apoE polymorphism on cholesterolemia in children with BW in the lowest tertilles.

Thus our data are in agreement with the studies of Garces et al. (2002) and Akisu et al. (2004), documenting the relationship of low $\mathrm{BW}$ and high cholesterol concentration in children and supporting Garces observation of greater effect of apoE genotype in individuals with $\mathrm{BW}$ in the lowest tertille.

ApoE gene and intrauterine undernutrition, might affect the development of higher cholesterol concentration either independently or simultaneously. If the effect of intrauterine undernutrition would be dominant and independent, then the frequency of disadvantage apoE4+ genotype in HCG group would increase from the lowest BW tertille (where low BW is mostly expressed) to the highest one (with normal BW). Since this is not the case (on the contrary, a slight opposite trend was documented), we conclude that the effect of both factors is rather synergic.

We suggest that our data were affected by rather strong environmental effects of the diet consumed in the Czech society at the time of this study (1988). The inconsistency of results regarding intrauterine programming to high TC by undernutrition may be caused by differences in individual genetic-environmental interactions. We would like to hypothesize that individuals less sensitive to environmental effects on TC concentration are also less sensitive to intrauterine undernutrition, whereas in our group of selected hypercholesterolemic individuals the effect was manifested. Intrauterine undernutrition seems to play a more important role in children of parents with polygenic hypercholesterolemia or with positive CHD history.

\section{Conflict of Interest}

There is no conflict of interest.

\section{Acknowledgements}

This work was supported by grant NR 7900-5 and NE 6536-7 from the Internal Grant Agency of the Czech Ministry of Health. 


\section{References}

AKISU M, BALIM Z, CETIN H, KOSOVA B, YALAZ M, TOPCUOGLU N, KULTURSAY N: The role of angiotensin-converting enzyme and apolipoprotein-E gene polymorphism on lipid compositions in newborn infants with intrauterine growth restriction. Early Hum Dev 78: 95-103, 2004.

BARKER DJP, HALES CN, FALL CHD, OSMOND C, PHIPPS K, CLARK PMS: Type 2 (non-insulin dependent) diabetes mellitus, hypertension and hyperlipidaemia (syndrom $\mathrm{X}$ ): relation to reduced fetal growth. Diabetologia 36: 62-67, 1993a.

BARKER DJP, MARTYN CN, OSMOND C, HALES CN, FALL CHD: Growth in utero and serum cholesterol concentrations in adult life. BMJ 307: 1524-1527, 1993b.

BARKER DJP: Fetal origins of coronary heart disease. BMJ 311: 171-174, 1995.

GARCES C, BENAVENTE M, ORTEGA H, RUBIO R, LASUNCION MA, RODRIGUEZ ARTALEJO F, FERNANDEZ PARDO J, DE OYA M: Influence of birth weight on the apo E determinants of plasma lipid levels in children. Pediatr Res 52: 873-878, 2002.

HAHN P: Late effects on early nutrition. In: Atherosclerosis: a Pediatric Perspective, M.T.R. SUBBIAH (ed.), CRC Press, Boca Raton, 1989, pp 155-164.

HIXSON JE, VERNIER D: Restriction isotyping of human apoprotein E by gene amplification and clearage with Hhal. J Lipid Res 31: 545-548, 1990.

HUBÁČEK JA, PISTULKOVÁ H, ŠKODOVÁ Z, LÁNSKÁ V, POLEDNE R. Antagonistic effect of insertion/deletion polymorphisms (HpaI) in the regulatory part of the apolipoprotein $\mathrm{CI}$ gene in children with high and low plasma cholesterol levels. Cas Lek Cesk 143: 94-96, 2004.

JONES SE, NYENGAARD JR: Low birth weight and cardiovascular disease: myth or reality. Curr Opin Lipidol 9: 309-312, 1998.

LAW CM, DE SWIET M, OSMOND C, FAYERS PM, BARKER DJP, CRUDDAS AM, FALL CHD: Initiation of hypertension in utero and its amplification throughout life. BMJ 306: 24-27, 1993.

LUMEN L, STEIN A: Offspring birth weight after maternal intrauterine undernutrition: a comparison within sibships. Am J Epidemiol 146: 801-809, 1997.

0'SULLIVAN J, WRIGHT C, PEARCE MS: The influence of age and gender on the relationship between birth weight and blood pressure in childhood. A study using 24-hour and casual blood pressure. Eur J Pediatr 161: 423$427,2002$.

PHILLIPS DIW, BARKER DJP, HALES CN, HIRST S, OSMOND C: Thinness at birth and insulin resistance in adult life. Diabetologia 37: 150-154, 1994.

PISTULKOVÁ H, POLEDNE R, KAUCKÁ J, ŠKODOVÁ Z, PETRŽÍLKOVÁ Z, PACLT M, VALENTA Z, GRAFNETTER D, PÍŠA Z: Cholesterolemia in school-age children and hypercholesterolemia aggregation in the family. CorVasa 33: 139-149, 1991.

POLEDNE R, HUBÁCEK J, PÍŠA Z, PISTULKOVÁ H, VALENTA Z: Genetic markers in hypercholesterolemic and normocholesterolemic Czech children. Clin Genet 16: 88-91, 1994.

STANNER SA, BULMER K, ANDRES C, LANTSEVA OE, BORODINA V, PATEEN W, YUDKIN JS: Does malnutrition in utero determine diabetes and coronary heart disease in adulthood? Results from the Leningrad Siege Study, a cross sectional study. BMJ 315: 1342-1349, 1997.

SZITÁNYI P, HANZLOVÁ J, POLEDNE R: Influence of intrauterine undernutrition on the development of hypercholesterolemia in an animal model. Physiol Res 49: 721-724, 2000.

WHINCUP P, COOK D, PAPCOSTA D, WALKER M: Birth weight and blood pressure: cross sectional and longitudinal relations in children. BMJ 311: 773-779, 1995. 